\title{
Nephron-sparing Techniques Independently Decrease the Risk of Cardiovascular Events Relative to Radical Nephrectomy in Patients with a T1a-T1b Renal Mass and Normal Preoperative Renal Function
}

\author{
Umberto Capitanio $^{a, b, *}$, Carlo Terrone $^{c}$, Alessandro Antonelli ${ }^{d}$, Andrea Minervini $^{e}$, \\ Alessandro Volpe ${ }^{c}$, Maria Furlan $^{d}$, Rayan Matloob ${ }^{a, b}{ }^{\text {, Federica Regis }}{ }^{c}$, Cristian Fiori $^{f}$, \\ Francesco Porpiglia $^{f}$, Ettore Di Trapani ${ }^{a, b}$, Monica Zacchero $^{c}$, Sergio Serni $^{e}$, Andrea Salonia $^{a, b}$, \\ Marco Carini $^{e}$, Claudio Simeone $^{d}$, Francesco Montorsi $^{a, b}$, Roberto Bertini $^{a, b}$

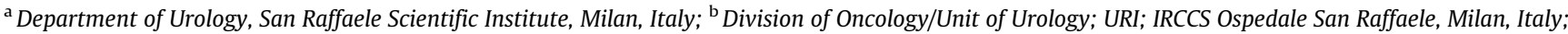 \\ ${ }^{\mathrm{c}}$ Department of Urology, University of Piemonte Orientale, Novara, Italy; ${ }^{\mathrm{d}}$ Department of Urology, Università degli studi e Spedali Civili di Brescia, Brescia, \\ Italy; ${ }^{\mathrm{e}}$ Department of Urology, Clinica Urologica I, Azienda Ospedaliera Universitaria Careggi, Università degli studi di Firenze, Florence, Italy; ${ }^{\mathrm{f}}$ Department of \\ Urology, AOU San Luigi Gonzaga, Università degli studi di Torino, Orbassano, Italy
}

Article info

Article history:

Accepted September 18, 2014

Keywords:

Nephron-sparing surgery

Radical nephrectomy

Partial nephrectomy

Cardiovascular event

Overall survival

Kidney cancer

\begin{abstract}
Background: Some reports have suggested that nephron-sparing surgery (NSS) may protect against cardiovascular events (CVe) when compared with radical nephrectomy (RN). However, previous studies did not adjust the results for potential selection bias secondary to baseline cardiovascular risk.

Objective: To test the effect of treatment type (NSS vs RN) on the risk of developing CVe after accounting for individual cardiovascular risk.

Design, setting, and participants: A multi-institutional collaboration including 1331 patients with a clinical T1a-T1b N0 M0 renal mass and normal renal function before surgery (defined as an estimated glomerular filtration rate $\geq 60 \mathrm{ml} / \mathrm{min} / 1.73 \mathrm{~m}^{2}$ ).

Intervention: $\mathrm{RN}(n=462,34.7 \%)$ or NSS $(n=869,65.3 \%)$ between 1987 and 2013.

Outcome measurement and statistical analyses: CVe was defined as onset during the follow-up period of coronary artery disease, cardiomyopathy, hypertension, vasculopathy, heart failure, dysrhythmias, or cerebrovascular disease not known before surgery. Cox regression analyses were performed. To adjust for inherent baseline differences among patients, we performed multivariate analyses adjusting for all available characteristics depicting the overall and cardiovascular-specific profile of the patients.

Results and limitations: When stratifying for treatment type, the proportion of patients who experienced CVe at 1,5 , and $10 \mathrm{yr}$ was $5.5 \%, 9.9 \%$, and $20.2 \%$ for NSS patients compared to $8.7 \%, 15.6 \%$, and $25.9 \%$, respectively, for RN patients $(p=0.001)$. In multivariate analyses, patients who underwent NSS showed a significantly lower risk of developing CVe compared with their RN counterparts (hazard ratio $0.57,95 \%$ confidence interval $0.34-0.96 ; p=0.03$ ) after accounting for clinical characteristics and cardiovascular profile. Limitations include the retrospective design of the study because other potential confounders may exist.
\end{abstract}

* Corresponding author. Department of Urology, San Raffaele Scientific Institute, via Olgettina 60, 20132 Milan, Italy. Tel. +39 02 26437286; Fax: +39 0226437298.

E-mail address: umbertocapitanio@gmail.com (U. Capitanio). 
Conclusions: The risk of CVe after renal surgery is not negligible. Patients treated with NSS have roughly half the risk of developing CVe relative to their RN counterparts. After accounting for clinical characteristics, comorbidities, and cardiovascular risk at diagnosis, NSS independently decreases the risk of CVe relative to RN.

Patient summary: The risk of having a cardiovascular event after renal surgery decreases if a portion of the affected kidney is spared.

(C) 2014 European Association of Urology. Published by Elsevier B.V. All rights reserved.

\section{Introduction}

Although nephron-sparing surgery (NSS) is still underutilized as treatment for patients with renal cell carcinoma (RCC), especially in nonacademic hospitals [1,2], basic research findings and clinical data have recently suggested that NSS may decrease the probability of cardiovascular events (CVe) after renal surgery when compared with radical nephrectomy $(\mathrm{RN})[3,4]$. Moreover, NSS offers the additional benefits of greater preservation of renal function and less overtreatment of benign tumors and clinically indolent malignancies [5]. However, the apparent benefit in performing NSS might have been the result of unmeasured confounding selection biases, such as clinical characteristics and, specifically, individual cardiovascular risk [6,7]. Indeed, the presence of hypertension, diabetes, smoking habit, and impaired preoperative renal function may affect decisions to select one surgical approach over the other, and these factors need to be considered to accurately define the potential benefit in performing NSS. Similarly, the controversial prospective results reported for the European Organization for Research and Treatment of Cancer (EORTC) 30904 trial showing no benefit of NSS in terms of survival might have been affected by major biases, mainly involving poor accrual and crossover between treatment arms [8].

The current multi-institutional study represents the first attempt to test the effect of treatment type (NSS vs RN) on the risk of CVe development after accounting for individual preoperative cardiovascular risk besides clinical tumor and patient characteristics.

\section{Patients and methods}

\subsection{Study population}

A multi-institutional collaboration among four European tertiary care centers allowed retrospective collection of data for 1973 patients with normal preoperative renal function (defined as estimated glomerular filtration rate $[\mathrm{eGFR}] \geq 60 \mathrm{ml} / \mathrm{min} / 1.73 \mathrm{~m}^{2}$ ) who underwent surgical treatment between 1987 and 2013 for a clinical T1a-T1b N0 M0 renal mass. Among these, complete data and details regarding preoperative cardiovascular profile and follow-up information were available for 1331 patients. Patients treated with NSS underwent open, laparoscopic, and robot-assisted surgery in 605 (69.6\%), 148 (17.0\%), and 116 (13.3\%) cases, respectively.

\subsection{Clinical and pathological evaluation}

A dedicated genitourinary pathologist examined the surgical specimens at each single tertiary care center. TNM stages were assigned according to the 2009 American Joint Committee on Cancer/Union Internationale Contre le
Cancer classification (AJCC/UICC) [9]. Cases before the introduction of the most recent classification scheme were reclassified. Clinical tumor size was based on preoperative imaging and was defined as the greatest tumor diameter in centimeters. GFR was calculated according to the Chronic Kidney Disease Epidemiology Collaboration (CKD-EPI) formula for younger patients $(<70 \mathrm{yr})[10]$ and the Berlin Initiative Study (BIS1) formula for older patients [11].

\subsection{Outcome}

CVe was defined as onset during the follow-up period of new coronary artery disease, cardiomyopathy, vasculopathy, hypertension, heart failure, dysrhythmias, or cerebrovascular disease not known before surgery and requiring hospitalization. Intraoperative or perioperative onset of CVe (up to $2 \mathrm{wk}$ after surgery) was not considered as an event. The treating physician or cardiologist defined the CVe type. CVe was assessed in the NSS and RN groups by scrutinizing subsequent hospital admissions charts or during periodic follow-up visit or, alternatively, by phone call if a patient was referred to another hospital after surgery. Information regarding the total CVe number after surgery for every patient was not available in all the centers, so the primary outcome was defined as the onset of at least one new CVe.

\subsection{Statistical analyses}

Statistical analyses and reporting and interpretation of the results were conducted according to recently published guidelines [12]. First, descriptive statistics were used to categorize the baseline characteristics among patients treated with either NSS or RN. The Kaplan-Meier method was used to depict the rate of CVe over the time. Second, to test the hypothesis that treatment type may affect the risk of CVe after surgery, univariate and multivariate Cox regression analyses were performed. To adjust for inherent baseline differences among patients, we included age, year of surgery, preoperative and postoperative GFR, clinical tumor size, clinical stage (cT1a vs cT1b), gender, symptoms (none vs local vs systemic), hypertension (none vs controlled by medication vs not controlled by medication), diabetes, baseline Charlson comorbidity index (CCI; 0 vs 1-2 vs $\geq 3$ ), body mass index (BMI), and smoker status as covariates.

Postoperative GFR is strongly related to treatment type (NSS vs RN), so the effect of postoperative renal function on CVe risk was also tested. The relationship between postoperative GFR and the outcome of interest is probably nonlinear, so the GFR effect on CVe was modeled using restricted cubic splines with knots at the tertiles. The curve was controlled for all confounders included in the above-mentioned multivariate model and stratified according to the treatment delivered. Confidence intervals (CIs; 95\%) are presented.

Statistical tests were performed using SPSS version 20 (IBM Corp., Somers, NY, USA). All tests were two-sided with a significance level set at $p<0.05$.

\section{Results}

Table 1 shows the clinical, surgical, and pathologic characteristics of the patients. Patients underwent RN $(n=462$, $34.7 \%$ ) or NSS ( $n=869,65.3 \%)$. The median follow-up period 
Table 1 - Descriptive statistics for 1331 patients diagnosed with renal cell carcinoma stratified according to the type of treatment

\begin{tabular}{|c|c|c|c|c|}
\hline & Total $(n=1331)$ & NSS $(n=869)$ & $\mathrm{RN}(n=462)$ & $p$ value \\
\hline \multicolumn{5}{|l|}{ Clinical characteristics } \\
\hline Age at diagnosis (yr) & $62(53-70)$ & $62(53-70)$ & $62(54-70)$ & $0.4^{\mathrm{a}}$ \\
\hline Body mass index $\left(\mathrm{kg} / \mathrm{m}^{2}\right)$ & $26.0(23.8-28.0)$ & $25.6(23.6-28.0)$ & $26.0(24.0-28.0)$ & $0.2^{\mathrm{a}}$ \\
\hline Gender (\%) & & & & $0.05^{\mathrm{b}}$ \\
\hline Male & 66.6 & 70.1 & 64.8 & \\
\hline Female & 33.4 & 29.9 & 35.2 & \\
\hline Smoker (\%) & 14.7 & 16.2 & 22.9 & $0.002^{\mathrm{b}}$ \\
\hline Hypertension (\%) & & & & $<0.001^{\mathrm{b}}$ \\
\hline None & 55.4 & 55.7 & 55.0 & \\
\hline HT not controlled by medication & 14.7 & 17.1 & 10.0 & \\
\hline HT controlled by therapy & 29.9 & 27.2 & 35.0 & \\
\hline Diabetes (\%) & 11.1 & 11.9 & 9.5 & $0.2^{\mathrm{b}}$ \\
\hline Creatinine at diagnosis (mg/dl) & $0.89(0.76-1.00)$ & $0.88(0.73-1.00)$ & $0.90(0.79-1.00)$ & $0.08^{\mathrm{a}}$ \\
\hline \multicolumn{5}{|l|}{ GFR $\left(\mathrm{ml} / \mathrm{min} / 1.73 \mathrm{~m}^{2}\right)$} \\
\hline At diagnosis & $84(70-96)$ & $85(70-98)$ & $81(70-93)$ & $0.02^{\mathrm{a}}$ \\
\hline At last follow-up & $73(58-87)$ & $78(64-93)$ & $62(52-76)$ & $<0.001^{\mathrm{a}}$ \\
\hline Charlson comorbidity index (\%) & & & & $<0.001^{\mathrm{b}}$ \\
\hline 0 & 62.5 & 66.3 & 55.4 & \\
\hline $1-2$ & 27.6 & 24.4 & 33.5 & \\
\hline$\geq 3$ & 9.9 & 9.3 & 11.0 & \\
\hline Symptoms at diagnosis (\%) & & & & $<0.001^{\mathrm{b}}$ \\
\hline None & 60.6 & 68.2 & 46.1 & \\
\hline Local & 32.3 & 27.0 & 42.2 & \\
\hline Systemic & 7.1 & 4.7 & 11.7 & \\
\hline Clinical tumor size $(\mathrm{cm})$ & $3.7(2.7-5.0)$ & $3.0(2.3-4.0)$ & $5.0(4.0-6.0)$ & $<0.001^{\mathrm{a}}$ \\
\hline Clinical tumor stage (\%) & & & & $<0.001^{\mathrm{b}}$ \\
\hline cT1a & 60.0 & 75.9 & 30.1 & \\
\hline cT1b & 40.0 & 24.1 & 69.9 & \\
\hline \multicolumn{5}{|l|}{ Surgical characteristics } \\
\hline Operating time (min) & $140(110-180)$ & $135(109-180)$ & $150(120-185)$ & $<0.001^{\mathrm{a}}$ \\
\hline Ischemia time, NSS only (min) & $15(8-20)$ & $15(8-20)$ & - & - \\
\hline
\end{tabular}

for uncensored cases was $52 \mathrm{mo}$ (interquartile range 25-90 mo). At 1,5 , and $10 \mathrm{yr}$, the proportion of patients who experienced CVe was $7.1 \%, 12.6 \%$, and $21.8 \%$, respectively. When stratifying for treatment type (NSS vs RN), the proportion of patients who experienced a CVe was 5.5\% versus $8.7 \%$ at $1 \mathrm{yr}, 9.9 \%$ versus $15.6 \%$ at $5 \mathrm{yr}$, and $20.2 \%$ versus $25.9 \%$ at $10 \mathrm{yr}$, respectively ( $p=0.001$; Fig. 1 ).

According to univariate analysis, treatment type (NSS vs RN) was strongly associated with CVe (hazard ratio [HR] $0.65,95 \%$ confidence interval [CI] 0.49-0.87; $p=0.003$ ). Similarly, patient age, comorbidities, symptoms, diabetes, hypertension, smoker status, and preoperative and postoperative GFR were associated with CVe risk during the follow-up period (all $p<0.05$ ).

In multivariate analyses (Table 2), patients who underwent NSS showed a significantly lower risk of developing CVe compared with their RN counterparts (HR 0.57, 95\%CI $0.34-0.96 ; p=0.03$ ) after accounting for clinical characteristics and cardiovascular profile. Figure 2 shows the multivariate predicted probability of $\mathrm{CVe}$ according to renal function after surgery and stratified for the type of treatment. For NSS, the CVe risk remained stably low in patients with normal function after surgery (GFR $\geq 60 \mathrm{ml} /$ $\mathrm{min} / 1.73 \mathrm{~m}^{2}$ ). A higher CVe risk was observed in NSS patients who developed any grade of CKD during the followup period (GFR $<60 \mathrm{ml} / \mathrm{min} / 1.73 \mathrm{~m}$ ). Conversely, in RN cases, CVe risk was slightly increased even in patients with normal renal function, reaching a plateau in patients who developed severe CKD $\left(<45 \mathrm{ml} / \mathrm{min} / 1.73 \mathrm{~m}^{2}\right)$.

\section{Discussion}

NSS is currently the standard of care for patients who are candidates for surgery for a clinical T1 renal mass when technically feasible [13-15]. It has been demonstrated that NSS is equivalent to RN in terms of cancer control [8, 16-19]. Although conservative surgery may be more challenging, especially for larger and more complex tumors [20], NSS is associated with better functional outcomes when compared to RN [21]. Finally, recent data have suggested a potential benefit in terms of decreasing the risk of subsequent CVe in patients treated with NSS in comparison to RN. Specifically, three categories of evidence suggesting an effect of NSS on cardiovascular risk are now available. First, recent basic research findings demonstrate that atherosclerotic lesions and collagen deposits are significantly increased in mice treated with RN compared with mice that underwent partial nephrectomy or sham operations [4]. Second, it has been demonstrated that RN is associated with lower postoperative GFR levels relative to NSS (level 1b evidence) [22] and that the risk of CVe also decreases directly with eGFR $[23,24]$. In addition, reduced 


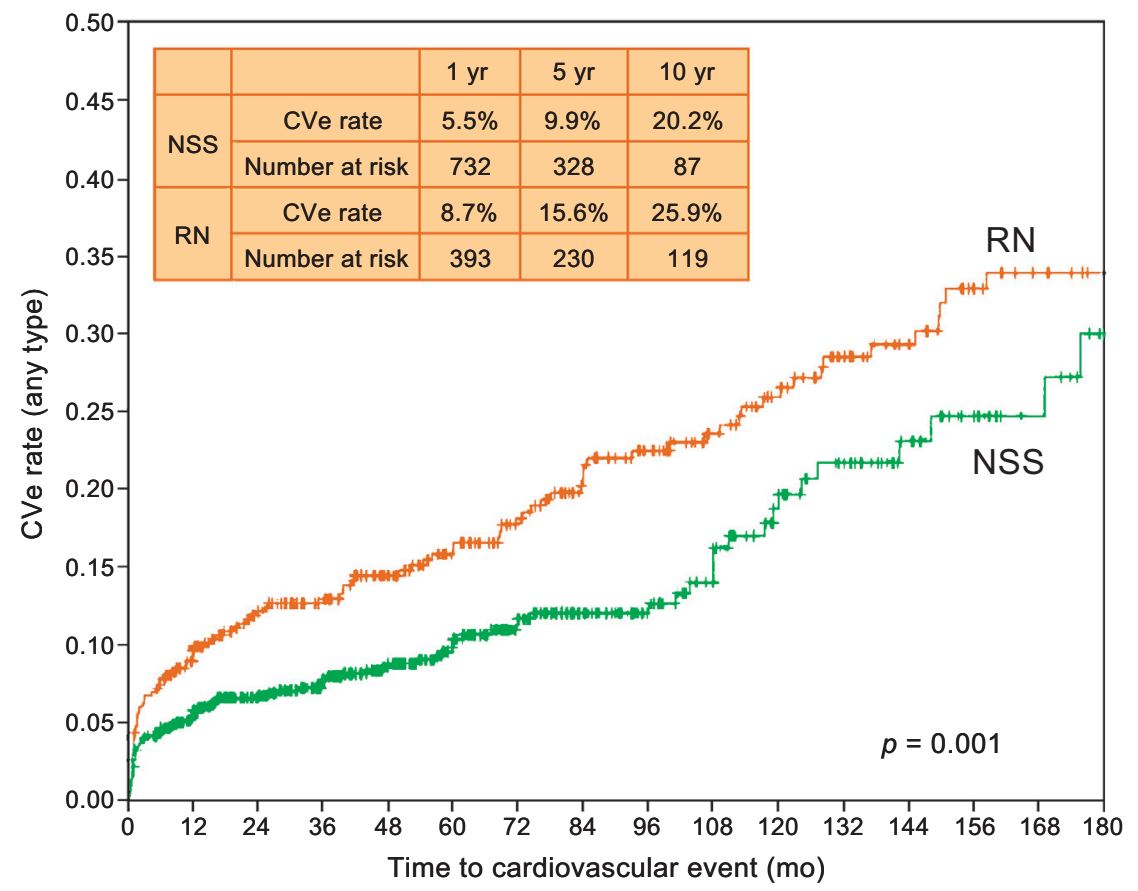

Fig. 1 - Kaplan-Meier curve depicting the rate of cardiovascular events (CVe) stratified according to the type of surgery. CVe was defined as onset during the follow-up period of coronary artery disease, cardiomyopathy, hypertension, heart failure, dysrhythmias, or cerebrovascular disease not known before surgery. RN = radical nephrectomy; NSS = nephron-sparing surgery.

kidney function has been associated with other cardiovascular risk factors (eg, increased levels of inflammatory factors [25], high apolipoprotein levels, anemia [26], left ventricular hypertrophy, increased arterial calcification

Table 2 - Multivariate Cox regression analyses predicting the onset of cardiovascular events in the total patient cohort

\begin{tabular}{|c|c|c|}
\hline & HR (95\% CI) & $p$ value \\
\hline Type of treatment (NSS vs RN) & $0.57(0.34-0.96)$ & 0.03 \\
\hline \multicolumn{3}{|l|}{ Preoperative characteristics } \\
\hline Preoperative GFR & $0.99(0.98-1.01)$ & 0.5 \\
\hline Age & $1.02(0.99-1.05)$ & 0.1 \\
\hline Gender (male vs female) & $1.21(0.74-1.98)$ & 0.4 \\
\hline Year of surgery & $1.15(1.08-1.23)$ & $<0.001$ \\
\hline Charlson comorbidity index & & 0.04 \\
\hline $1-2$ versus 0 & $1.51(0.91-2.51)$ & 0.1 \\
\hline$\geq 3$ versus 0 & $2.15(1.11-4.17)$ & 0.02 \\
\hline Symptoms at diagnosis & & $<0.001$ \\
\hline Local versus none & $3.26(1.98-5.34)$ & $<0.001$ \\
\hline Systemic versus none & $5.13(2.73-9.64)$ & $<0.001$ \\
\hline Clinical tumor size & $0.91(0.70-1.18)$ & 0.5 \\
\hline Clinical stage (cT1b vs cT1a) & $1.18(0.52-2.63)$ & 0.7 \\
\hline \multicolumn{3}{|l|}{ Cardiovascular profile } \\
\hline Diabetes & $0.77(0.38-1.58)$ & 0.4 \\
\hline Postoperative GFR & $0.99(0.98-1.01)$ & 0.4 \\
\hline Hypertension & & 0.007 \\
\hline $\begin{array}{l}\text { HT not controlled by } \\
\text { medication versus none }\end{array}$ & $2.26(1.23-4.14)$ & 0.009 \\
\hline $\begin{array}{l}\text { HT controlled by } \\
\text { medication versus none }\end{array}$ & $0.77(0.45-1.32)$ & 0.3 \\
\hline Body mass index & $1.04(0.98-1.10)$ & 0.2 \\
\hline Smoker status & $1.06(0.80-1.40)$ & 0.7 \\
\hline
\end{tabular}

[27,28], endothelial dysfunction, and arterial stiffness $[29,30])$. Third, population-based studies have revealed a greater number of CVe in patients treated with $\mathrm{RN}$ in comparison to NSS [3,31]. For instance, Huang et al [3] analyzed the Surveillance, Epidemiology, and End Results (SEER)-Medicare cancer registry and collected data for 2991 patients treated with NSS (19\%) or RN (81\%) between 1995 and 2002. For a mean follow-up period of 43 mo they reported a CVe rate of $20 \%$ after surgery, similar to the current study, with a 1.4-fold greater number of events after $\mathrm{RN}(p<0.05)$. Besides the relatively low number of NSS patients and the short follow-up period, unfortunately the authors could not adjust their results for tumor size, smoker status, and BMI, all possible confounders for patient selection and potential CVe predictors. Moreover, the majority of published studies have relied on US patient cohorts. Few data are available regarding the effect of NSS on CVe risk in European patients, who typically show a lower risk of cardiovascular death relative to their US counterparts [32]. Specifically, differences in patient lifestyles and diets and a potential dissimilar baseline genetic environment may play a role in evaluation of the effect of NSS on CVe risk.

Conversely, other reports did not confirm a difference in the rate of CVe after surgery. Miller et al [33] performed a retrospective cohort study based on linked SEER-Medicare data. The authors identified 10886 patients who underwent NSS or RN between 1991 and 2002 and calculated propensity scores to balance the treatment cohorts with respect to measured patient and disease characteristics. The likelihood of adverse cardiovascular outcomes did not differ by treatment [33]. Recently, Shuch et al [34] noted a 


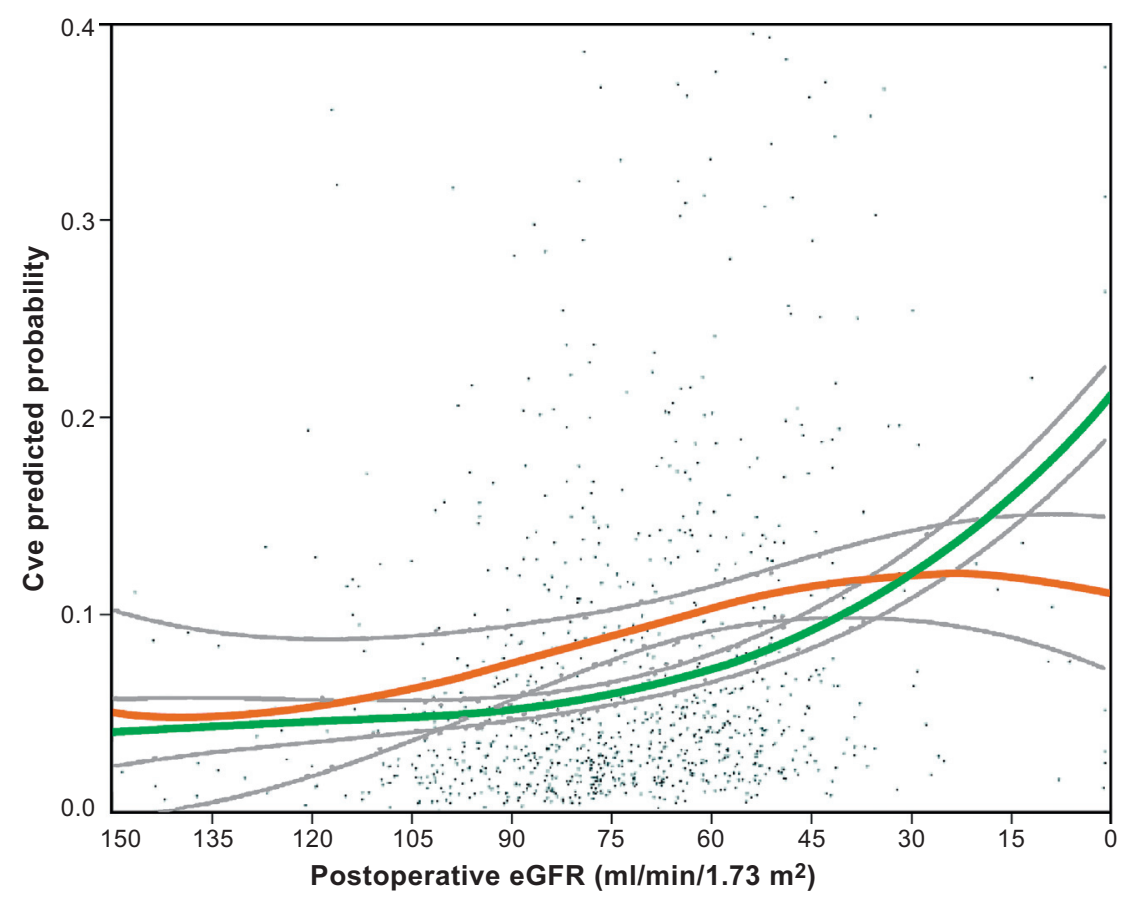

Fig. 2 - Multivariate predicted probability of a cardiovascular event (CVe) according to renal function after surgery. Green line, nephron-sparing surgery; orange line, radical nephrectomy; gray lines, $95 \%$ confidence intervals. The curve is controlled for all confounders included in the full multivariate model (age, year of surgery, preoperative clinical tumor size, clinical stage, gender, symptoms, hypertension, diabetes, baseline Charlson comorbidity index, body mass index, and smoker status). eGFR = estimated glomerular filtration rate.

2.5-fold increased risk of CVe in patients treated with NSS or RN compared to noncancer controls $(p<0.0001)$. Unfortunately, they did not directly compare the two treatments to verify a difference in the risk of cardiovascular events associated with one type of treatment for RCC [34].

For the first time, we performed an adjusted comparison between patients with T1 renal masses treated with either NSS or RN after accounting for the individual cardiovascular profile before surgery, as well as clinical and tumor characteristics. We demonstrated that the risk of CVe after renal surgery is not negligible and that NSS independently decreases the risk of CVe relative to $\mathrm{RN}$, even after accounting for potential confounders and selection biases that were not considered in previous studies. The importance of these findings is even greater in the context of novel strategies such as active surveillance, which have been gaining in popularity for treatment of small masses, especially for older and sicker patients.

Finally, we confirmed the importance of postoperative GFR levels for the risk of developing CVe after surgery. Preservation of renal function is one of the most important aims when NSS is pursued. Moreover, a significant part of the CVe risk benefit secondary to NSS can probably be attributed to the protective effect of NSS on postoperative GFR. In the current study, interesting data emerged when the effect of postoperative GFR on CVe risk was stratified for treatment type (NSS vs RN) and analyzed in nonlinear multivariate modeling (Fig. 2). Specifically, after accounting for all the available baseline and cardiovascular confounders, CVe risk remained stably low in NSS patients with normal renal function after surgery (GFR $\geq 60 \mathrm{ml} / \mathrm{min} / 1.73 \mathrm{~m}^{2}$ ). Higher CVe risk was observed in patients treated with NSS who developed any grade of CKD (GFR $<60 \mathrm{ml} / \mathrm{min} / 1.73 \mathrm{~m}^{2}$ ) during the follow-up period. Conversely, CVe risk was slightly increased in RN patients with normal renal function, reaching a plateau in those who developed severe CKD $\left(<45 \mathrm{ml} / \mathrm{min} / 1.73 \mathrm{~m}^{2}\right)$. These results may be because NSS protects renal function against surgically induced CKD and that the higher CVe risk is probably subsequent to the development of CKD secondary to a medical condition, independent of previous surgery (eg, new onset of diabetes or other metabolic syndromes). Conversely, in RN patients we probably observed a combination of both the conditions (surgically induced CKD and possible secondary medical CKD) and a gradual increase in CVe risk secondary to a decrease in postoperative GFR. Finally, at very low GFR levels the CVe risk was higher for NSS than for RN patients. This is probably because in NSS patients with T1 cancers, end-stage CKD is secondary to medical conditions in the majority of cases since nephrons are largely spared during surgery. Conversely, in RN patients the surgically induced loss of nephrons accounts for a substantial proportion of the pathogenesis of end-stage CKD and, as recently demonstrated by Lane and colleagues [35], surgically induced CKD is usually associated with a lower risk of clinical progression than medical CKD.

Our study provides a fairer comparison of CVe risk between NSS and RN for the first time because we took into account many confounders that were not included in previous reports (eg, hypertension not controlled by 
medication, diabetes, smoker status, BMI). Besides its strengths, the retrospective nature of the study is certainly a limitation. Specifically, as was the case for the majority of the data available on the topic, the results could not be adjusted for other potential confounders, such as hyperlipidemia, exercise activity, and alcohol use, or for possible differences in terms of follow-up assessment between the two cohorts.

\section{Conclusions}

The risk of CVe after renal surgery is not negligible. Patients treated with NSS have roughly half the risk of developing CVe relative to their RN counterparts. NSS independently decreases the risk of $\mathrm{CVe}$ relative to $\mathrm{RN}$, even after accounting for clinical characteristics, comorbidities, and cardiovascular risk at diagnosis.

Author contributions: Umberto Capitanio had full access to all the data in the study and takes responsibility for the integrity of the data and the accuracy of the data analysis.

Study concept and design: Capitanio, Terrone, Antonelli, Minervini, Volpe, Fiori, Simeone, Bertini.

Acquisition of data: Capitanio, Terrone, Antonelli, Minervini, Volpe, Furlan, Matloob, Regis, Fiori, Porpiglia, Di Trapani, Zacchero, Serni, Salonia, Carini, Simeone, Montorsi, Bertini.

Analysis and interpretation of data: Capitanio, Terrone, Antonelli, Minervini, Volpe, Furlan, Matloob, Regis, Fiori, Porpiglia, Di Trapani, Zacchero, Serni, Salonia, Carini, Simeone, Montorsi, Bertini.

Drafting of the manuscript: Capitanio, Terrone, Antonelli, Minervini, Volpe, Fiori.

Critical revision of the manuscript for important intellectual content: Capitanio, Terrone, Antonelli, Minervini, Volpe, Furlan, Matloob, Regis, Fiori, Porpiglia, Di Trapani, Zacchero, Serni, Salonia, Carini, Simeone, Montorsi, Bertini.

Statistical analysis: Capitanio, Montorsi, Bertini.

Obtaining funding: None.

Administrative, technical, or material support: None.

Supervision: Capitanio, Terrone, Antonelli, Minervini, Volpe, Furlan, Matloob, Regis, Fiori, Porpiglia, Di Trapani, Zacchero, Serni, Salonia, Carini, Simeone, Montorsi, Bertini.

Other (specify): None.

Financial disclosures: Umberto Capitanio certifies that all conflicts of interest, including specific financial interests and relationships and affiliations relevant to the subject matter or materials discussed in the manuscript (eg, employment/affiliation, grants or funding, consultancies, honoraria, stock ownership or options, expert testimony, royalties, or patents filed, received, or pending), are the following: None.

Funding/Support and role of the sponsor: None.

\section{References}

[1] Hollenbeck BK, Taub DA, Miller DC, Dunn RL, Wei JT. National utilization trends of partial nephrectomy for renal cell carcinoma: a case of underutilization? Urology 2006;67:254-9.

[2] Miller DC, Hollingsworth JM, Hafez KS, Daignault S, Hollenbeck BK. Partial nephrectomy for small renal masses: an emerging quality of care concern? J Urol 2006;175:853-7.

[3] Huang WC, Elkin EB, Levey AS, Jang TL, Russo P. Partial nephrectomy versus radical nephrectomy in patients with small renal tumors-is there a difference in mortality and cardiovascular outcomes? J Urol 2009;181:55-61.

[4] Ivanovski O, Nikolov I, Davceva O, Gjorgjievska K, Janevska V, Petrusevska G. Partial nephrectomy may protect from future cardiovascular disease-first experimental evidence. Paper presented at: EAU 9th South Eastern European Meeting (SEEM); Thessaloniki, Greece; 2013.

[5] Filson CP, Schwartz K, Colt JS, et al. Use of nephron-sparing surgery among renal cell carcinoma patients with diabetes and hypertension. Urol Oncol 2014;32, 27.e15-e21.

[6] Kutikov A, Smaldone MC, Uzzo RG. Partial versus radical nephrectomy: balancing nephrons and perioperative risk. Eur Urol 2013;64: 607-9.

[7] Kim SP, Thompson RH, Boorjian SA, et al. Comparative effectiveness for survival and renal function of partial and radical nephrectomy for localized renal tumors: a systematic review and meta-analysis. J Urol 2012;188:51-7.

[8] Van Poppel H, Da Pozzo L, Albrecht W, et al. A prospective, randomised EORTC intergroup phase 3 study comparing the oncologic outcome of elective nephron-sparing surgery and radical nephrectomy for low-stage renal cell carcinoma. Eur Urol 2011; 59:543-52.

[9] Sobin LH, Gospodarowicz MK, Wittekind C. International Union against Cancer. TNM classification of malignant tumours. ed. 7. Hoboken, NJ: Wiley-Blackwell; 2010.

[10] Skali H, Uno H, Levey AS, Inker LA, Pfeffer MA, Solomon SD. Prognostic assessment of estimated glomerular filtration rate by the new Chronic Kidney Disease Epidemiology Collaboration equation in comparison with the Modification of Diet in Renal Disease Study equation. Am Heart J 2011;162:548-54.

[11] Schaeffner ES, Ebert N, Delanaye P, et al. Two novel equations to estimate kidney function in persons aged 70 years or older. Ann Intern Med 2012;157:471-81.

[12] Vickers AJ, Sjoberg DD. Guidelines for reporting of statistics in European Urology. Eur Urol 2015;67:181-7.

[13] Ljungberg B, Cowan NC, Hanbury DC, et al. EAU guidelines on renal cell carcinoma: the 2010 update. Eur Urol 2010;58:398-406.

[14] Escudier B, Eisen T, Porta C, et al. Renal cell carcinoma: ESMO clinical practice guidelines for diagnosis, treatment and follow-up. Ann Oncol 2012;23(Suppl 7):vii65-71.

[15] Campbell SC, Novick AC, Belldegrun A, et al. Guideline for management of the clinical T1 renal mass. J Urol 2009;182:1271-9.

[16] Antonelli A, Ficarra V, Bertini R, et al. Elective partial nephrectomy is equivalent to radical nephrectomy in patients with clinical T1 renal cell carcinoma: results of a retrospective, comparative, multiinstitutional study. BJU Int 2012;109:1013-8.

[17] Capitanio U, Zini L, Perrotte P, et al. Cytoreductive partial nephrectomy does not undermine cancer control in metastatic renal cell carcinoma: a population-based study. Urology 2008;72: 1090-5.

[18] Crepel M, Jeldres C, Sun M, et al. A population-based comparison of cancer-control rates between radical and partial nephrectomy for T1A renal cell carcinoma. Urology 2010;76:883-8.

[19] Zini L, Perrotte P, Capitanio U, et al. Radical versus partial nephrectomy: effect on overall and noncancer mortality. Cancer 2009;115: 1465-71.

[20] Jeldres C, Patard JJ, Capitanio U, et al. Partial versus radical nephrectomy in patients with adverse clinical or pathologic characteristics. Urology 2009;73:1300-5.

[21] Scosyrev E, Messing EM, Sylvester R, Campbell S, Van Poppel H. Renal function after nephron-sparing surgery versus radical nephrectomy: results from EORTC randomized trial 30904. Eur Urol 2014;65:372-7. 
[22] Scosyrev E, Messing E, Campbell S. Radical versus partial nephrectomy for a small renal mass: does saving nephrons save lives? Expert Rev Anticancer Ther 2013;13:1349-51.

[23] Go AS, Chertow GM, Fan D, McCulloch CE, Hsu CY. Chronic kidney disease and the risks of death, cardiovascular events, and hospitalization. N Engl J Med 2004;351:1296-305.

[24] Takeshita H, Yokoyama M, Fujii Y, et al. Impact of renal function on cardiovascular events in patients undergoing radical nephrectomy for renal cancer. Int J Urol 2012;19:722-8.

[25] Shlipak MG, Fried LF, Crump C, et al. Elevations of inflammatory and procoagulant biomarkers in elderly persons with renal insufficiency. Circulation 2003;107:87-92.

[26] Hsu CY, McCulloch CE, Curhan GC. Iron status and hemoglobin level in chronic renal insufficiency. J Am Soc Nephrol 2002;13: 2783-6.

[27] Raggi P, Boulay A, Chasan-Taber S, et al. Cardiac calcification in adult hemodialysis patients. A link between end-stage renal disease and cardiovascular disease? J Am Coll Cardiol 2002;39: 695-701.

[28] London GM, Guerin AP, Marchais SJ, Metivier F, Pannier B, Adda H. Arterial media calcification in end-stage renal disease: impact on all-cause and cardiovascular mortality. Nephrol Dial Transplant 2003;18:1731-40.
[29] Levin A, Djurdjev O, Barrett B, et al. Cardiovascular disease in patients with chronic kidney disease: getting to the heart of the matter. Am J Kidney Dis 2001;38:1398-407.

[30] Blacher J, Safar ME, Guerin AP, Pannier B, Marchais SJ, London GM. Aortic pulse wave velocity index and mortality in end-stage renal disease. Kidney Int 2003;63:1852-60.

[31] Weight CJ, Larson BT, Fergany AF, et al. Nephrectomy induced chronic renal insufficiency is associated with increased risk of cardiovascular death and death from any cause in patients with localized cT1b renal masses. J Urol 2010;183:1317-23.

[32] Levi F, Lucchini F, Negri E, La Vecchia C. Trends in mortality from cardiovascular and cerebrovascular diseases in Europe and other areas of the world. Heart 2002;88:119-24.

[33] Miller DC, Schonlau M, Litwin MS, Lai J, Saigal CS. Urologic Diseases in America Project. Renal and cardiovascular morbidity after partial or radical nephrectomy. Cancer 2008;112:511-20.

[34] Shuch B, Hanley JM, Lai JC, et al. Adverse health outcomes associated with surgical management of the small renal mass. J Urol 2014;191:301-8.

[35] Lane BR, Campbell SC, Demirjian S, Fergany AF. Surgically induced chronic kidney disease may be associated with a lower risk of progression and mortality than medical chronic kidney disease. J Urol 2013;189:1649-55.

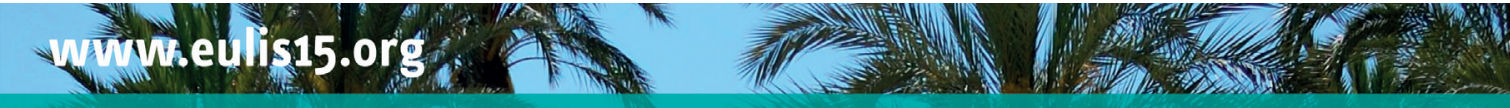 \\ EULIST5 \\ 3rd Meeting of the \\ EAU Section of Urolithiasis}

10-12 September 2015, Alicante, Spain

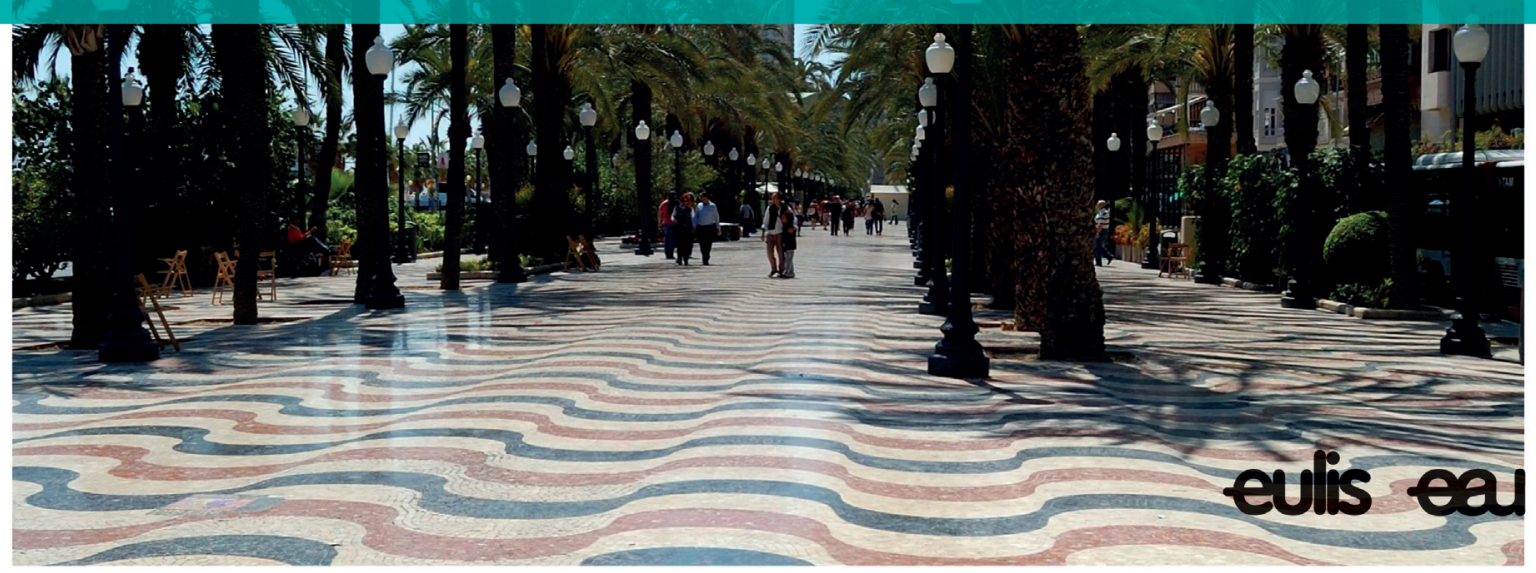

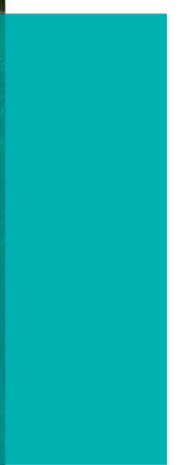

EAU Events are accredited by the EBU in compliance with the UEMS/EACC
regulations 